\title{
HUBUNGAN NILAI P300 DENGAN MOCA-INA PADA PASIEN DENGAN GANGGUAN KOGNITIF VASKULAR PASCASTROKE ISKEMIK
}

\author{
ASSOCIATION OF P300 VALUE WITH MOCA-INA IN VASCULAR COGNITIVE \\ IMPAIRMENT POST-ISCHEMIC STROKE PATIENTS \\ Susilo, * Yudy Goysal, ** Abdul Muis, ** Muhammad Akbar,** Andi Kurnia Bintang, ** Burhanuddin Bahar, *** \\ Muhammad Iqbal Basri**
}

\section{ABSTRACT}

Introduction: Stroke is a major threat in human life because it can cause disability and mortality. Cognitive impairment in early stroke is strong predictor for long term vascular cognitive impairment while neuropsychology method is superior than conventional method to diagnose cognitive impairment, especially P300.

Aim: To identify the association between P300 values and MoCA-Ina in vascular cognitive impairment post ischemic stroke patients.

Methods: It is a cross sectional design study for ischemic stroke patients who suffered from vascular cognitive impairment during April to June 2018 in Neurology Clinic of Dr. Wahidin Sudirohusodo Hospital, Makassar. The statistical analysis was performed by Pearson's correlation test.

Result: There were 20 samples, male (60\%) and female (40\%). The average MoCA-Ina score was 19.35 \pm 6.06; the average P300 latency in $\mathrm{Fz}, \mathrm{Cz}$, and $\mathrm{Pz}$ were $370.22 \pm 49.01 \mathrm{~ms}, 360.78 \pm 38.27 \mathrm{~ms}$, and $361.02 \pm 44.45 \mathrm{~ms}$, respectively; the average P300 in $\mathrm{Fz}, \mathrm{Cz}$, and $\mathrm{Pz}$ amplitude were $6.09 \pm 3.10 \mu \mathrm{V}, 5.67 \pm 3.49 \mu \mathrm{V}$, and $6.10 \pm 2.77 \mu \mathrm{V}$, respectively. The Pearson's showed that P300 latency had significantly correlation with MoCA-Ina score while no correlation between the P300 amplitude and MoCA-Ina.

Discussion: There was correlation between P300 latency with MoCA-Ina in vascular cognitive impairment post ischemic stroke patients.

Keywords: Ischemic stroke, MoCA-Ina, P300 value, vascular cognitive impairment.

\section{ABSTRAK}

Pendahuluan: Stroke merupakan suatu ancaman terbesar di kehidupan manusia karena dapat menimbulkan kecacatan dan kematian. Gangguan kognitif pada awal stroke merupakan prediktor kuat untuk gangguan kognitif vaskular jangka panjang dan metode neuropsikologi lebih unggul daripada metode konvensional untuk mendiagnosis gangguan kognitif, terutama P300.

Tujuan: Untuk mengetahui hubungan nilai P300 dengan MoCA-Ina pada pasien gangguan kognitif vaskular pascastroke iskemik.

Metode: Desain studi potong lintang terhadap pasien stroke iskemik yang mengalami gangguan kognitif vaskular selama bulan April sampai Juni 2018 di Poliklinik Saraf RSUP Dr. Wahidin Sudirohusodo, Makassar. Data diolah menggunakan uji korelasi Pearson's.


hasil rata-rata latensi gelombang $\mathrm{P} 300 \mathrm{di} \mathrm{Fz}, \mathrm{Cz}$, dan $\mathrm{Pz}$ masing-masing adalah 370,22 $\pm 49,01,360,78 \pm 38,27$, dan

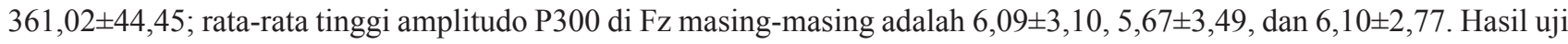
korelasi Pearson's menunjukkan latensi P300 berkorelasi signifikan terhadap MoCA-Ina, sedangkan amplitudo P300 tidak.

Pembahasan: Ada hubungan antara latensi gelombang P300 dengan MoCA-Ina pada pasien gangguan kognitif vaskular pascastroke iskemik.

Kata kunci: Gangguan kognitif vaskular, MoCA-Ina, nilai P300, stroke iskemik

*Bagian Neurologi FK Universitas Hasanuddin, Makassar; Bagian Ilmu Kesehatan Masyarakat Fakultas Kesehatan Masyarakat Universitas Hasanuddin, Makassar. Korespondensi: susilo_starforce@yahoo.com.

\section{PENDAHULUAN}

Stroke merupakan suatu ancaman terbesar di kehidupan manusia karena dapat menimbulkan kecacatan dan bahkan data nasional menunjukkan angka kematian tertinggi yaitu $15,4 \%$. Di Indonesia prevalensi stroke dari 7 per-mil menjadi 12,1 permil. Prevalensi perprovinsi didapatkan yang tertinggi berturut-turut yaitu di Sulawesi Selatan (17,9 permil), DI Yogyakarta (16,9 per-mil), Sulawesi Tengah (16,6 per-mil), diikuti Jawa Timur (16 per-mil). ${ }^{1}$ 
Sekitar $82-92 \%$ adalah stroke iskemik atau infark. ${ }^{2}$

Salah satu ancaman kecatatan adalah stroke sebagai penyebab utama terjadinya gangguan kognitif vaskular. Hachinski dan Bowler pertama kali menggambarkan konsep vascular cognitive impairment (VCI) sebagai istilah dasar yang mencakup semua tingkat penurunan kognitif yang terkait dengan cerebrovascular disease (CVD). ${ }^{3}$ Small vessels disease (SVD) merupakan penyebab gangguan kognitif vaskular yang paling sering. ${ }^{4}$ Gangguan kognitif merupakan prediktor kuat untuk keluaran fungsional yang buruk pada pasien stroke karena dapat mengganggu proses rehabilitasi dan menjadi beban ekonomi. ${ }^{5-6}$

Prevalensi VCI sangat bervariasi, namun penelitian menunjukkan bahwa sebanyak 12-56\% pasien stroke mengalami gangguan kognitif. ${ }^{6} \mathrm{Di}$ Indonesia sebuah penelitian di RS Atma Jaya, Jakarta melaporkan bahwa dari 60 pasien stroke iskemik akut didapatkan $61,7 \%$ mengalami gangguan kognitif berdasarkan Mini-Mental State Examination (MMSE) dan 78,3\% berdasarkan Montreal Cognitive Assessment (MoCA-Ina). ${ }^{7}$

Instrumen skrining untuk masalah kognitif sering digunakan MMSE. Beberapa penelitian melaporkan validitas MMSE dapat diterima pada pasien stroke, namun yang lain menyimpulkan bahwa ini bukan alat skrining yang akurat pada pasien stroke, karena tidak dapat membedakan antara lesi fokal dan umum, tergantung pada bahasa, usia, dan pendidikan. ${ }^{8}$ Instrumen lainnya adalah Montreal Cognitive Assessment (MoCA), yang merupakan alat skrining kognitif yang sederhana dan berdiri sendiri dengan sensitivitas dan spesifisitas yang baik dalam mendeteksi dan mengevaluasi gangguan kognitif pada fase akut stroke, kelebihannya adalah menilai fungsi eksekutif dibandingkan MMSE. Namun keterbatasan pemeriksaan MoCA yaitu sulitnya peneliti membandingkan terhadap penelitian lain karena perbedaan latar belakang demografik dan karakteristik diantara populasi, selain itu juga pada kasus stroke ringan, gangguan kognitif ini sulit terdeteksi karena terkendala pada fase stroke hiperakut dan $\operatorname{mood}$ pasien. ${ }^{9}$
Salah satu penilaian neurofisiologi yang dapat dilakukan adalah pemeriksaan event-related evoked potentials (ERP), terutama P300. Pemeriksaan P300 mudah dilakukan, dapat sering diulang, tidak ada efek samping radiasi yang tidak diinginkan, dan aplikasinya mudah. Juga, pemeriksaan ini tidak bias, dan tidak dipengaruhi hasil individual. ${ }^{10} \mathrm{P} 300$ auditorik ditandai oleh gelombang amplitudo yang besar, yang dihasilkan oleh diskriminasi ekspektasi (dalam perhatian) mengenai apa yang disebut stimulus langka (target), yang bertentangan dengan stimulus yang sering (standar), dan muncul kira-kira pada $300 \mathrm{~ms}$ setelah awitan stimulus. Pada penelitian sebelumnya dilaporkan adanya peningkatan latensi dan pengurangan amplitudo P300 pada pasien Alzheimer's Disease (AD) dan gangguan kognitif ringan. ${ }^{11}$

Latensi P300 menunjukkan evaluasi dari stimulasi selama aktivitas kognitif, dan berhubungan dengan rata-rata proses informasi, sedangkan amplitudo mengindikasikan tingkat mobilisasi sumber daya efektif ketika otak menerima informasi, dan juga mengindikasikan eksitabilitas dari otak. Hasil studi Jiang B dkk mengonfirmasi bahwa pemanjangan latensi P300 secara objektif merefleksikan gangguan fungsi kognitif ringan, dan fenomena ini dapat digunakan untuk menentukan gangguan fungsi kognitif yang berkaitan dengan gangguan fungsi neurologis setelah stroke. Namun tidak ditemukan hubungan bermakna pada amplitudo P300. Gangguan fungsi kognitif pada pasien stroke dapat didiagnosis lebih dini dengan menggabungkan tes neurologis dan tes P300 sehingga dapat memfasilitasi intervensi sewaktu-waktu dan memperbaiki prognosis. ${ }^{12}$

Penelitian ini bertujuan untuk mengetahui hubungan nilai P300 dengan gangguan kognitif vaskular pada pasien stroke iskemik.

\section{METODE}

Penelitian dilaksanakan April hingga Juli 2018. Tempat penelitian di Poliklinik Saraf RSUP Dr. Wahidin Sudirohusodo, Makassar. Penelitian ini merupakan jenis penelitian dengan desain potong lintang. Sampel penelitian ditentukan dengan cara consecutive sampling. Subjek yang memenuhi kriteria 
inklusi penelitian dan telah memberikan informed consent diikutsertakan dalam penelitian. Kriteria inklusi adalah pasien stroke iskemik yang menderita gangguan kognitif vaskular dalam kurun waktu 3 bulan. Kriteria eksklusi adalah skizofrenia, depresi, alkoholisme. Dilakukan anamnesis, pemeriksaan CT scan kepala, pemeriksaan MoCA-Ina, dan pemeriksaan ERP auditorik (P300). Apabila pasien tidak dapat membedakan bunyi pada pemeriksaan ERP auditorik maka pasien akan dikeluarkan dari penelitian. Variabel yang dinilai pada pemeriksaan P300 adalah latensi (millisecond $/ \mathrm{ms}$ ) dan amplitudo (microvolt $/ \mu \mathrm{V})$.

Data yang diperoleh dianalisis dengan SPSS versi 21. Uji statistik korelasi Pearson's dilakukan untuk mengetahui adanya hubungan antara nilai P300 dengan gangguan kognitif vaskular pada pasien stroke iskemik. Penilaian uji hipotesis dinyatakan bermakna apabila $p \leq 0,05$. Penelitian ini telah disetujui oleh Komite Etik Penelitian Kesehatan FK Universitas Hasanuddin.

\section{HASIL}

Selama periode penelitian diperoleh 20 orang penderita stroke iskemik dengan gangguan kognitif vaskular yang memenuhi kriteria inklusi. Karakteristik subjek penelitian meliputi usia, jenis kelamin, tingkat pendidikan, dan awitan dapat dilihat pada Tabel 1.

Tabel 1. Karakteristik Sampel Penelitian Berdasarkan Jenis Kelamin, Tingkat Pendidikan dan Awitan ( $\mathrm{n}=\mathbf{2 0})$

\begin{tabular}{lcc}
\hline \multicolumn{1}{c}{ Karakteristik } & Jumlah & Persentase (\%) \\
\hline $\begin{array}{l}\text { Jenis Kelamin } \\
\text { - Laki-laki }\end{array}$ & 12 & 60 \\
- Perempuan & 8 & 40 \\
$\begin{array}{l}\text { Tingkat Pendidikan } \\
\text { - Dasar (SD dan SMP) }\end{array}$ & 4 & 20 \\
- Menengah (SMA dan & 10 & 50 \\
$\quad$ Diploma) & & \\
- Tinggi (S1, S2, dan S3) & 6 & 30 \\
$\begin{array}{l}\text { Awitan (Hari) } \\
\text { - } \quad \leq 14\end{array}$ & 12 & 60 \\
- $15-30$ & 4 & 20 \\
- $\geq 31$ & 4 & 20 \\
\hline
\end{tabular}

Variabel hasil penelitian dapat dilihat pada Tabel 2 yang menunjukkan mean dari usia, nilai MoCA-Ina, awitan serangan stroke saat pasien diperiksa, latensi P300 (Fz, Cz, dan Pz), amplitudo P300 (Fz, Cz, dan Pz), dan komponen MoCA-Ina (visuospasial/ eksekusi, penamaan, atensi, bahasa, abstraksi, delayed recall, dan orientasi).

Hasil uji korelasi menggunakan uji Pearson's menunjukkan adanya korelasi yang signifikan bermakna pada nilai latensi $\mathrm{Fz}, \mathrm{Cz}$, dan $\mathrm{Pz}$ terhadap MoCA-Ina. Namun tidak terdapat korelasi antara amplitudo pada $\mathrm{Fz}, \mathrm{Cz}$, dan $\mathrm{Pz}$ terhadap MoCAIna (Tabel 3). Masing-masing komponen MoCAIna dilakukan uji korelasi Pearson's. Komponen visuospasial/eksekusi, penamaan, atensi, dan bahasa memiliki hubungan yang bermakna dengan latensi P300, namun tidak bermakna dengan amplitudo P300. Komponen abstraksi dan delayed recall tidak terdapat hubungan bermakna baik pada latensi maupun amplitudo P300. Komponen orientasi memiliki hubungan yang bermakna terhadap latensi P300, amplitudo P300 di Cz dan Pz, namun tidak berhubungan dengan amplitudo P300 di Fz (Tabel 4).

\section{PEMBAHASAN}

Penelitian ini menunjukkan bahwa terdapat hubungan bermakna antara nilai latensi P300 dengan MoCA-Ina pada pasien gangguan kognitif vaskular pascastroke iskemik, tetapi tidak ada hubungan bermakna antara nilai amplitudo P300 dengan MoCA-Ina pada pasien gangguan kognitif vaskular pascastroke iskemik.

Pada penelitian ini didapatkan nilai latensi P300 yang memanjang ( $>300 \mathrm{~ms})$. Jiang, B menemukan rata-rata latensi $\mathrm{P} 300$ adalah $379,12 \pm 25,68 \mathrm{~ms}$ dan amplitudo $4,04 \pm 0,75 \mu \mathrm{V}$ pada pasien gangguan kognitif vaskular pasca iskemik stroke tanpa demensia. Sedangkan Madjidova \& Khaydarova menemukan nilai rata-rata latensi peak $\mathrm{P} 300$ sebesar $374 \mathrm{~ms}$ dan nilai rata-rata peak amplitudo sebesar $5,2 \mu \mathrm{V}$ pada pasien Mild Cognitive Impairment dengan iskemia serebral kronik. ${ }^{17}$ Beberapa studi menunjukkan hal yang serupa dengan penelitian ini, yaitu pemanjangan latensi P300 pada pasien dengan gangguan kognitif vaskular. 
Tabel 2. Karakteristik Pemeriksaan P300 dan MoCA-Ina (n=20)

\begin{tabular}{|c|c|c|c|c|}
\hline Variabel & Minimum & Maksimum & Mean & Std Deviation \\
\hline Usia & 22 & 65 & 50 & 11,55 \\
\hline MoCA-Ina & 4 & 25 & 19,35 & 6,06 \\
\hline Awitan (Hari) & 4 & 60 & 19,35 & 16,14 \\
\hline \multicolumn{5}{|l|}{ Latensi P300 (ms) } \\
\hline - $\mathrm{Fz}$ & 340,3 & 529,7 & 370,22 & 49,01 \\
\hline - $\mathrm{Cz}$ & 331,9 & 456,3 & 360,78 & 38,27 \\
\hline - $\mathrm{Pz}$ & 320,3 & 492,2 & 361,02 & 44,45 \\
\hline \multicolumn{5}{|l|}{ Amplitudo P300 $(\mu \mathrm{V})$} \\
\hline - $\mathrm{Fz}$ & 0,54 & 10,25 & 6,09 & 3,1 \\
\hline - $\mathrm{Cz}$ & 0,85 & 11,57 & 5,67 & 3,49 \\
\hline - $\mathrm{Pz}$ & 2,31 & 12,95 & 6,1 & 2,77 \\
\hline \multicolumn{5}{|l|}{ Komponen MoCA-Ina } \\
\hline - Visuospasial/eksekusi & 0 & 4 & 2,45 & 1,5 \\
\hline - Penamaan & 0 & 3 & 2,3 & 0,92 \\
\hline - Atensi & 0 & 6 & 3,6 & 2,06 \\
\hline - Bahasa & 0 & 3 & 1,7 & 1,08 \\
\hline - Abstraksi & 0 & 2 & 0,95 & 0,88 \\
\hline - Delayed recall & 0 & 5 & 2,85 & 1,69 \\
\hline - Orientasi & 4 & 6 & 5,35 & 0,81 \\
\hline
\end{tabular}

MoCA-Ina: Montreal Cognitive Assessment versi Indonesia; Fz: frontal midline; Cz: central midline; Pz: parietal midline.

Tabel 3. Hubungan Nilai Latensi dan Amplitudo P300 dengan Nilai MoCA-Ina (n=20)

\begin{tabular}{ccccccccc}
\hline \multirow{2}{*}{$\begin{array}{c}\text { Uji Pearson's } \\
\text { Fz }\end{array}$} & \multicolumn{3}{c}{ Latensi P300 } & \multicolumn{3}{c}{ Amplitudo P300 } \\
\cline { 2 - 8 } & & $\mathbf{F z}$ & $\mathbf{C z}$ & $\mathbf{P z}$ & $\mathbf{F z}$ & $\mathbf{C z}$ & $\mathbf{P z}$ \\
\hline \multirow{2}{*}{ MoCA-Ina } & $\mathrm{r}$ & $-0,690$ & $-0,685$ & $-0,729$ & 0,18 & 0,242 & 0,25 \\
& $\mathrm{p}$ & 0,001 & 0,001 & $<0,001$ & 0,447 & 0,305 & 0,287 \\
\hline
\end{tabular}

Uji Pearson's; MoCA-Ina: Montreal Cognitive Assessment versi Indonesia; Fz: frontal midline; Cz: central midline; Pz: parietal midline.

Nilai MoCA-Ina berkorelasi negatif dengan nilai latensi P300 secara signifikan yang berarti semakin rendah nilai MoCA-Ina akan semakin panjang nilai latensi P300. Hasil penelitian ini juga sesuai dengan penelitian Jiang dan Byang menemukan adanya korelasi signifikan bermakna yang berbanding terbalik pada skor MoCA-Ina dengan latensi P300 yang berarti semakin rendah skor MoCA-Ina akan semakin tinggi latensi P300. Namun tidak ada korelasi yang bermakna signifikan antara skor MoCA-Ina dengan amplitudo. Pada penelitian ini tidak didapatkan hubungan yang bermakna antara nilai amplitudo P300 dengan gangguan kognitif vaskular pada pasien stroke iskemik meskipun terdapat kecenderungan bahwa semakin tinggi nilai MoCA-Ina, semakin tinggi amplitudo P300. Hal ini mungkin karena sampel yang didapatkan mempunyai nilai MoCA-Ina yang cukup baik atau menderita gangguan kognitif ringan sehingga pada beberapa sampel yang mempunyai gangguan kognitif berat baru didapatkan penurunan amplitudo. Sementara itu kecenderungan ini sesuai dengan penelitian lainnya yaitu ada penurunan nilai MoCA-Ina diikuti dengan penurunan amplitudo P300. Sensitivitas nilai latensi P300 cukup tinggi sehingga terjadi pemanjangan latensi yang signifikan meskipun gangguan kognitif vaskular yang terjadi bersifat ringan. Hal ini sesuai dengan penelitian lainnya yang mengatakan bahwa selain pada demensia, pemeriksaan P300 juga dapat dilakukan pada kasus gangguan kognitif ringan bahkan silent cerebral infarction. Sehingga pemeriksaan ini menjadi modalitas yang penting 
Tabel 4. Hubungan Nilai Latensi dan Amplitudo P300 dengan Komponen MoCA-Ina ( $n=20)$

\begin{tabular}{lccccccc}
\hline \multirow{2}{*}{ Uji Pearson's } & \multicolumn{3}{c}{ Latensi P300 } & \multicolumn{3}{c}{ Amplitudo P300 } \\
\cline { 2 - 7 } Visuospasial/eksekusi & & $\mathbf{F z}$ & $\mathbf{C z}$ & $\mathbf{P z}$ & $\mathbf{F z}$ & $\mathbf{C z}$ & $\mathbf{P z}$ \\
\hline \multirow{2}{*}{ Penamaan } & $\mathrm{r}$ & $-0,597$ & $-0,554$ & $-0,585$ & 0,148 & 0,244 & 0,159 \\
& $\mathrm{p}$ & 0,041 & 0,038 & 0,04 & 0,789 & 0,407 & 0,633 \\
\multirow{2}{*}{ Atensi } & $\mathrm{r}$ & $-0,509$ & $-0,462$ & $-0,573$ & 0,156 & 0,12 & 0,14 \\
& $\mathrm{p}$ & 0,005 & 0,011 & 0,007 & 0,533 & 0,299 & 0,503 \\
\multirow{2}{*}{ Bahasa } & $\mathrm{r}$ & $-0,543$ & $-0,558$ & $-0,553$ & $-0,003$ & 0,076 & 0,161 \\
& $\mathrm{p}$ & 0,022 & 0,041 & 0,008 & 0,51 & 0,613 & 0,555 \\
Abstraksi & $\mathrm{r}$ & $-0,282$ & $-0,379$ & $-0,337$ & 0,05 & $-0,134$ & 0,002 \\
& $\mathrm{p}$ & 0,013 & 0,011 & 0,011 & 0,989 & 0,749 & 0,497 \\
Delayed recall & $\mathrm{r}$ & $-0,285$ & $-0,257$ & $-0,291$ & 0,239 & 0,193 & 0,131 \\
\multirow{2}{*}{ Orientasi } & $\mathrm{p}$ & 0,228 & 0,100 & 0,147 & 0,834 & 0,572 & 0,993 \\
& $\mathrm{r}$ & $-0,604$ & $-0,634$ & $-0,642$ & 0,303 & 0,529 & 0,564 \\
& $\mathrm{p}$ & 0,224 & 0,274 & 0,212 & 0,311 & 0,416 & 0,582 \\
& $\mathrm{r}$ & $-0,597$ & $-0,509$ & $-0,543$ & $-0,282$ & $-0,285$ & $-0,604$ \\
& $\mathrm{p}$ & 0,005 & 0,003 & 0,002 & 0,194 & 0,017 & 0,01 \\
\hline
\end{tabular}

Uji Pearson's; MoCA-Ina: Montreal Cognitive Assessment versi Indonesia; Fz: frontal midline; Cz: central midline; Pz: parietal midline.

dalam mendiagnosis secara dini pasien-pasien gangguan kognitif awal terutama pada pasien stroke iskemik.

Keterbatasan penelitian ini adalah tidak adanya kontrol dan jumlah pasien masih minimal sehingga tidak dapat membandingkan dengan pasien stroke tanpa gangguan kognitif vaskular.

\section{KESIMPULAN}

Peneliti menyimpulkan bahwa nilai latensi P300 mempunyai hubungan terhadap nilai MoCA-Ina pada pasien gangguan kognitif vaskular pascastroke iskemik. Peneliti menyarankan agar dilakukan penelitian lebih lanjut dengan menggunakan desain penelitian kohort untuk menilai perubahan nilai latensi dan amplitudo P300 terhadap perkembangan gangguan kognitif vaskular pada pasien stroke iskemik.

\section{DAFTAR PUSTAKA}

1. Kemenkes RI. Riset Kesehatan Dasar 2013; 2013.

2. Mozaffarian D, Benjamin EJ, Go AS, Arnett DK, Blaha MJ. Heart disease and stroke statistics-2015. Update: a report from the American Heart Association. Circulation. 2015;131(4):29-322.

3. Paul RH, Cohen R, Ott BR, Salloway S. Vascular dementia: cerebrovascular mechanisms and clinical management. New Jersey: Humana press; 2005.

4. Makin SDJ, Turpin S, Dennis MS, Wardlaw JM.
Cognitive impairment after lacunar stroke: systematic reviewand meta-analysis of incidence, prevalence and comparison with other stroke subtypes. J Neurol Neurosurg Psychiatry. 2013;84:893-900.

5. Lee M, Saver JL, Hong KS, Wu YL, Liu HC, Rao NM, dkk. Cognitive impairment and risk of future stroke: a systematic review and meta-analysis. CMAJ. 2014:186(14):536-46.

6. Siva PR, Rashij M. P300-a cognitive evaluation tool in acute ischemic stroke-a narrative review. Gulf Medical Journal. 2014;3(S2):165-71.

7. Carrey M, Darmawan O, Yolanda R, Arianti M, Sangwidjojo IA, Vania A, dkk. Prevalence of cognitive impairment in acute ischemic stroke patients in Atma Jaya Hospital Jakarta. Dalam Proceedings of $20^{\text {th }}$ Asia Pacific Regional Conference; 4 November 2017; Jakarta, Indonesia. London: Alzheimer's Disease International; 2017.

8. Bour A, Rasquin S, Boreas A, Limburg M, Verhey F. How predictive is the MMSE for cognitive performance after stroke? J Neurol. 2010;257:630-7.

9. Salvadori E, Pasi M, Poggesi A, Chiti G, Inzitari D, Pantoni L. Predictive value of MoCA in the acute phase of stroke on the diagnosis of mid-term cognitive impairment. J Neurol. 2013;260:2220-7.

10. Titlic M, Mihalj M, Petrovic AB, Suljic E. P300 as an auxiliary method in clinical practice: a review of literature. J Health Sci. 2016;6(3):143-8.

11. Pedrosso RV, Fraga FJ, Corazza DI, Andreatto CA, Coelho FG, Costa JL, dkk. P300 latency and amplitude in Alzheimer's disease: a systematic 
review. Braz J Otorhinolaryngol. 2012;78(4):126-32.

12. Jiang B, Yao G, Yao C, Zhang Y, Ge J, Qiu E. Vascular cognitive impairment with no dementia: neuropsycology, brain imaging, and event-related potentials. Neurophysiology. 2013;45(4):323-8.
13. Khaydarova DK, Madjidova YN. Study of the cognitive evoked potentials and bioelectrical brain activity in patients with mild cognitive impairment associated with chronic cerebral ischemia. International Journal of BioMedicine. 2013;3(3):18891. 